\title{
Commentary: Pleural metastases in thymic tumors: Is surgery the answer?
}

\author{
C. Corbin Frye, MD, M. Shea Harrison, MD, and Varun Puri, MD, MSCI
}

\footnotetext{
From the Division of Cardiothoracic Surgery, Department of Surgery, Washington University School of Medicine, St Louis, Mo.

Disclosures: Authors have nothing to disclose with regard to commercial support

Received for publication Oct 11, 2019; revisions received Oct 11, 2019; accepted for publication Oct 11, 2019; available ahead of print Dec 10, 2019.

Address for reprints: C. Corbin Frye, MD, 4909 Laclede Ave, \#1905, St Louis, MO, 63108 (E-mail: cfrye@wustl. edu).

J Thorac Cardiovasc Surg 2020;159:717-8

$0022-5223 / \$ 36.00$

Copyright (C) 2019 by The American Association for Thoracic Surgery

https://doi.org/10.1016/j.jtcvs.2019.10.059
}

This study, ${ }^{1}$ from a highly respected institution, reports long-term, postresection outcomes for thymic tumors with pleural metastases. The relatively low incidence of this clinical scenario makes it unsuitable for rigorous prospective study. The current series offers a relatively large sample size and clinically relevant data suggesting that carefully selected patients have good outcomes and achieve longterm survival with aggressive treatment.

The results in this study likely reflect a rigorous multidisciplinary evaluation and careful patient selection for surgery. However, with only data from patients who underwent resection, it is not possible to make generalizations about the overall cohort of patients with thymic tumors and pleural disease.

The differentiation between thymoma and thymic carcinoma, which are both included in the present study, may be apparent only after surgery, yet these tumors have vastly different prognoses. The authors noted a median survival of 11.8 years in patients with thymoma whereas patients with thymic carcinoma had a median survival of 5.5 years. ${ }^{1}$ Although 5.5 years is a longer median survival than for most other metastatic cancers, the study also revealed that none of the 15 patients were disease free after 3 years postoperatively, suggesting that surgeons should be extremely selective in offering resection to patients with stage 4 thymic carcinoma.

Novel technologies aimed at ablating microscopic disease are emerging as adjuvant therapies for thymoma and thymic carcinoma. Intraoperative hyperthermic chemotherapy, a well-described surgical technique in peritoneal carcinomatosis, can be applied in the thorax for pleural metastases. However, retrospective series show varying results, including a disappointing 0\% 5-year survival rate for patients with de novo stage IVa thymic cancer. ${ }^{2,3}$ Photodynamic therapy, which has been shown to provide a survival advantage in lung cancer, ${ }^{4,5}$ is a technique in which tumor cells are killed from direct exposure to light via a photosensitizer. In retrospective studies, photodynamic therapies.

\section{References}

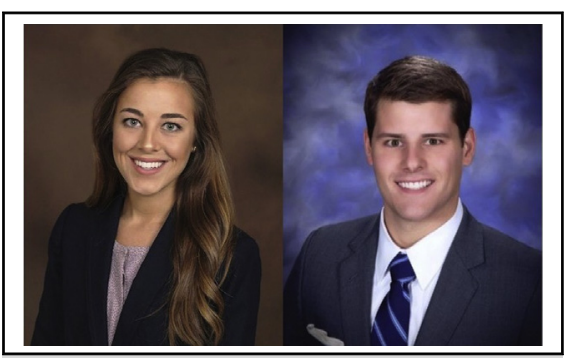

Left: M. Shea Harrison, MD; right: C. Corbin Frye, MD

\section{Central Message}

Thymoma and thymic cancer with pleural metastases can be treated with aggressive surgical therapy.

See Article page 705 .

therapy combined with surgery was associated with a $13 \%$ local recurrence rate for thymoma with pleural spread $^{6}$ and a $63 \%$ cure rate when combined with surgery for a curative intent. ${ }^{7}$ Thymic tumors have also been shown to have response to immunotherapy, most notably, pembrolizumab. Two phase II trials showed pembrolizumab to be associated with response rates of $19 \%$ to $23 \%$ and stable disease rates of $53 \%$ to $54 \%{ }^{8,9}$ However, severe autoimmune complications such as hepatitis, myocarditis, and myasthenia gravis occurred in more than $70 \%$ of thymoma patients. ${ }^{8,9}$ Although future studies are needed, it is possible that within the next decade, metastatic thymic malignancies will be routinely treated with these novel adjuvant

According to the National Cancer Institute, there are 10 ongoing trials regarding unresectable or metastatic thymic carcinoma and thymoma. ${ }^{10}$ All of them are investigating adjuvant immunotherapy and chemotherapy for unresectable tumors, and none of them have a treatment arm that includes surgical management. This shows not only the importance of the current study but also the need for future research and trials that focus on surgical management of these complex tumors.

1. Choe G, Ghanie A, Riely G, Rimner A, Park BJ, Bains MS, et al. Long-term, disease-specific outcomes of thymic malignancies presenting with de novo pleural metastasis. J Thorac Cardiovasc Surg. 2020;159:705-14.e1. 
2. Yu L, Jing Y, Ma S, Li F, Zhang Y-F. Cytoreductive surgery combined with hyperthermic intrapleural chemotherapy to treat thymoma or thymic carcinoma with pleural dissemination. Oncotargets Ther. 2013; 6:517-21.

3. Yellin A, Simansky DA, Ben-Avi R, Perelman M, Zeitlin N, Refaely Y, et al. Resection and heated pleural chemoperfusion in patients with thymic epithelial malignant disease and pleural spread: a single-institution experience. J Thorac Cardiovasc Surg. 2013;145:83-9.

4. Wang B-Y, Wu Y-C, Hung J-J, Hsu PK, Hsieh CC, Huang CS, et al. Prognosis of non-small-cell lung cancer with unexpected pleural spread at thoracotomy. J Surg Res. 2011;169:e1-5.

5. Mordant P, Arame A, Foucault C, Dujon A, Barthes F, Riquet M. Surgery for metastatic pleural extension of non-small-cell lung cancer. Eur J Cardiothorac Surg. 2011;40:1444-9.
6. Chen K-C, Hsieh Y-S, Tseng Y-F, Shieh MJ, Chen JS, Lai HS, et al. Pleural photodynamic therapy and surgery in lung cancer and thymoma patients with pleural spread. PloS One. 2015;10:e0133230.

7. Detterbeck F. International thymic malignancies interest group: a way forward. J Thorac Oncol. 2010;5:S365-70.

8. Cho J, Kim H, Ku B, Choi YL, Cristescu R, Han J, et al. Pembrolizumab for patients with refractory or relapsed thymic epithelial tumor: an open-label phase II trial. J Clin Oncol. 2018;37:2162-70.

9. Giaccone G, Kim C, Thompson J, McGuire C, Kallakury B, Chahine JJ, et al. Pembrolizumab in patients with thymic carcinoma: a single-arm, single-centre, phase 2 study. Lancet Oncol. 2018;19:347-55.

10. National Institute of Cancer. Clinical Trials to Treat Thymoma and Thymic Carcinoma. Available at: https://www.cancer.gov/about-cancer/treatment/clinicaltrials/thymoma-thymic-carcinoma. Accessed October 6, 2019. 